\title{
Binding of $o$-nitroaniline to nonaqueous AOT reverse micelles
}

\author{
R. Dario Falcone, Juana J. Silber,* M. Alicia Biasutti, and N. Mariano Correa* \\ Departamento de Química. Universidad Nacional de Río Cuarto. Agencia Postal \# 3. \\ C.P. X5804BYA Río Cuarto. Argentina \\ E-mail:jsilber@exa.unrc.edu.ar,.mcorrea@exa.unrc.edu.ar
}

\begin{abstract}
Dedicated to Professors Rita H. Rossi, Julio C. Podestá, Manuel González Sierra and Oscar S. Giordano, recognizing their achievements in organic chemistry and their contributions in the development of the field in the Argentine
\end{abstract}

\begin{abstract}
The binding of $o$-nitroaniline ( $o$-NA) to the micellar interface of $n$-heptane/1,4-bis(2-ethylhexyl) sulfosuccinate (AOT)/nonaqueous polar solvent reverse micelles was determined by UV-visible spectroscopy. As polar solvents: ethylene glycol (EG), formamide (FA), glycerol (GY), dimethylacetamide (DMA) and dimethylformamide (DMF) were used. The binding constant, $\mathrm{K}_{\mathrm{b}}$, obtained follow the order: DMF $\sim$ DMA $>$ FA $\sim \mathrm{W}_{S}=0>\mathrm{EG}>$ water $>$ GY. It is demonstrated that the $o$-NA - AOT hydrogen bond interaction is with the AOT sulfonate moiety. Thus, the more accessible that this group is for hydrogen bond interaction the larger is the $\mathrm{K}_{\mathrm{b}}$ value.
\end{abstract}

Keywords: nonaqueous reverse micelles, AOT, hydrogen bond, nitroaniline.

\section{Introduction}

Molecular interactions play an important role in molecular recognition and they are the main nucleus in supramolecular and combinatory chemistry. ${ }^{1}$ When surfactants assemble in non polar solvents they form supramolecular structures in which their polar or charged groups are located in the interior, or core, of the aggregate, while their hydrocarbon tails extend into the bulk solvent. ${ }^{2,3}$ Thus, water is readily solubilized in the polar core forming a water pool, which is characterized by $\mathrm{W}_{0}\left(\mathrm{~W}_{0}=\left[\mathrm{H}_{2} \mathrm{O}\right] /[\right.$ Surfactant $\left.]\right)$. The structures formed are generally known as "reversed micelles" or "water in oil microemulsions".-9 Among the surfactants capable of forming these aggregates, sodium 1,4-bis(2-ethylhexyl)sulfosuccinate (AOT, Scheme 1) is one of the most used. ${ }^{10}$ Solutions of AOT in nonpolar solvents have the remarkable ability to solubilize a large amount of water with values of $\mathrm{W}_{0}$ as large as 40 to $60,{ }^{11,12}$ depending on the surrounding nonpolar medium, the solute and the temperature. 
The solubilization dynamics of molecular probes by reverse micelles contribute to the general understanding of transport processes through more complex membrane structures. ${ }^{13}$ Consequently, solubilization of substrates in micellar aggregates plays an important role in biological and industrial processes. ${ }^{10}$

The main driving forces responsible for the solute distribution between the organized assembly and the organic medium are considered to be mainly hydrophobic effects and hydrogen bond interactions. ${ }^{14}$ However, other effects such as chemical and electrostatic interactions must be considered when charges ${ }^{15}$ or zwitterionic molecules ${ }^{16}$ are involved.

In these supramolecular systems, a solute can be located in a variety of microenvironments namely the surrounding organic solvent, the water pool or at the micellar interface. To know the location of molecular probes in the aggregates, can give information about their residing place in biological systems. ${ }^{6}$

We have previously studied the properties of a series of nitroanilines, ${ }^{17}$ diphenylamines, ${ }^{18}$ carotenoids ${ }^{19}$ and amines ${ }^{20}$ in reverse micelles of AOT in $n$-hexane or $n$-heptane at different $\mathrm{W}_{0}$. Two factors seem to be involved in the partition of these solutes in the micelles. One is the solubility in the organic medium and the other the hydrogen bond donor capacity of the probe. The latter seems to be the dominant factor. Thus, the partition constants of these solutes have their highest value when no water is added to the system $\left(\mathrm{W}_{0}=0\right)$ and bind to the polar head of the AOT. However upon addition of water, the partition constants diminish because there is a competition between the hydrogen bond donor solutes and water as solvating agent for the AOT. ${ }^{17-19}$

Besides water, some polar organic solvents, having high dielectric constants and very low solubility in hydrocarbon solvents, can also be encapsulated in reverse micelles. ${ }^{21}$ The most common polar solvents used include formamide (FA), dimethylformamide (DMF), dimethylacetamide (DMA), ethylene glycol (EG), propylene glycol (PG), and glycerol (GY). ${ }^{22-46}$ The reverse micelles in AOT/n-heptane systems containing these solvents are known to be spherical. Moreover, while the reverse micelles formed in the absence of water or other polar solvent possess a hydrodynamic radius of $\sim 1.5 \mathrm{~nm},{ }^{28}$ those containing nonaqueous polar solvent swell much more rapidly than those containing water, reaching a size similar to $\mathrm{W}_{0}=10$ (aqueous) with $\mathrm{W}_{S}=$ [polar solvents]/[AOT] $\sim 2$ (nonaqueous). ${ }^{29,33}$ Also, it has been demonstrated that the size of the reverse micelles depends on $\mathrm{W}_{S .}{ }^{23,29}$ In a recent communication ${ }^{47}$ we have shown using dynamic light scattering (DLS) that the GY, water, EG, DMF, DMA or FA/AOT/n-heptane reverse micelles droplet sizes depend on the different polar solvents-AOT interactions and not on their molar volume, $\mathrm{V}_{\mathrm{m}}$. The interactions can significantly affect the surfactant effective $a$ value with the consequent changes in the droplet sizes. Thus, we show that the micelle sizes are similar when hydrogen bond donor solvents are used and, they are larger than those created using non hydrogen bond donor solvents.

Recently ${ }^{48}$ using FT-IR, a noninvasive technique, we follow the changes in the AOT's C=O, symmetric and asymmetric $\mathrm{SO}_{3}{ }^{-}$vibration modes with the increase in the polar solvents content in the micelles. The results show that GY interacts through hydrogen bond with the $\mathrm{SO}_{3}{ }^{-}$group 
removing the $\mathrm{Na}^{+}$counterions from the interface remaining in the polar core of the micelles. PG and EG interact through hydrogen bond mainly with the AOT's $\mathrm{C}=\mathrm{O}$ group penetrating into the oil side of the interface. Thus, they interact weakly with the $\mathrm{Na}^{+}$counterion which seems to be close to the AOT sulfonate group. It was also demonstrated that FA encapsulated by AOT reverse micelles, interacts strongly with the $\mathrm{Na}^{+}$counterions of the surfactant through electrostatic interactions maintaining their hydrogen bond network present in the FA bulk. ${ }^{42}$ Finally, DMF and DMA encapsulated inside the reverse micelles, interact neither with the $\mathrm{C}=\mathrm{O}$ nor with the $\mathrm{SO}_{3}^{-}$groups but their weakly associated bulk structure is broken because the interactions with $\mathrm{Na}^{+}$. We suggest that DMF and DMA can complex the $\mathrm{Na}^{+}$ions through their carbonyl and nitrogen groups. Hence, our results give insights, not only in how the constrained environment affects the bulk properties of the polar solvents encapsulated inside the reverse micelles but, more important, give an idea about which region of the AOT moiety are involved in the polar solvents interactions.

In this work we determine the binding of $o$-nitroaniline (o-NA) to the micellar interface of $n$ heptane/AOT/polar solvent nonaqueous reverse micelles using as polar solvents: ethylene glycol (EG), formamide (FA), glycerol (GY), dimethylacetamide (DMA) and dimethylformamide (DMF). The aim is to establish the effect of a hydrogen bond donor solute, in the competition with different polar solvents toward the AOT interface. As it is known with which part of the AOT polar headgroup the different polar solvents interact, we also want to assess the specific AOT polar head group moiety where $o$-NA makes the hydrogen bond interaction. Moreover we obtain information about the factors that affect the solubility of this type of solute in these nonaqueous systems.<smiles>Nc1ccccc1[N+](=O)[O-]</smiles>

O-NA

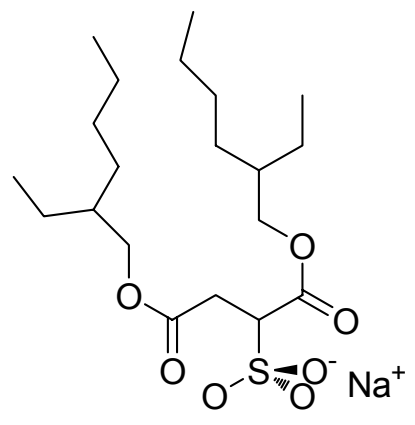

AOT

Scheme 1. Molecular structure of the molecular probe used: $o$-NA and the AOT surfactant.

\section{Results and Discussion}

Previous results have shown ${ }^{17}$ that the solvatochromic behavior of $o$-NA is mainly due to the solvent's polarity / polarizability $\left(\pi^{*}\right)$ and the capacity of the media to accept a proton $(\beta)$ in a 
solvent to solute hydrogen bond interaction. ${ }^{49}$ It was shown that the ratio between the coefficients $s$ and $b$ which measure the relative susceptibilities of $v$ to the indicated solvent property scale, $\pi^{*}$ and $\beta$, respectively, are almost equal to $1 .{ }^{17}$ In $n$-hexane/AOT/water reverse micelles it was found that $o$-NA binds to the polar heads of AOT through the NH groups in a hydrogen bond interaction and, the water addition decreases the binding constant $\mathrm{K}_{\mathrm{b}}$ up to $\mathrm{W}_{0}=$ 10 showing the competition of water for the polar heads of the surfactant. ${ }^{17}$ Nevertheless, it is interesting to discover with which part of the AOT polar head, namely the sulfonate or the ester moiety ${ }^{48} o$-NA interacts through hydrogen bond. Thus, we have chosen a set of polar solvents that interact with different parts of the AOT moiety including the $\mathrm{Na}^{+}$counterions. ${ }^{17}$

\section{Studies in n-Heptane/AOT Reverse Micelles}

When the absorption spectra of $o$-NA are studied in the reverse micellar system strong effects are observed varying AOT concentration at constant $\mathrm{W}_{\mathrm{s}}$. First, we will show the results in AOT reverse micelles without the addition of any polar solvents, i.e. $\mathrm{W}_{S}=0$ and then we will discuss the effect of the different polar solvent addition.

In Figure 1 typical spectra of $o$-NA in $n$-heptane/AOT reverse micelles as a function of AOT concentration at $\mathrm{W}_{S}=0$ are shown. As it can be observed, the intensity of the band at $\lambda_{\max }=376$ $\mathrm{nm}(\log \varepsilon=3.73)$, characteristic in $n$-heptane, decreases as the AOT concentration increases and a new band develops at $\lambda_{\max }=400 \mathrm{~nm}$. This band may be mostly due to the hydrogen bond formation between the $o$-NA and the polar head of AOT. ${ }^{17}$ The neat isosbestic point at $\lambda=384$ $\mathrm{nm}$ shows that an equilibrium between free $o$-NA in $n$-heptane and bound to the micelle interface was established. For AOT concentration greater than $0.05 \mathrm{M}$ the absorption spectrum remains unchanged. Consequently, at this concentration it can be considered that the probe is fully bound to the micelle and a value of $\log \varepsilon=3.74$ for the $400 \mathrm{~nm}$ band can be calculated.

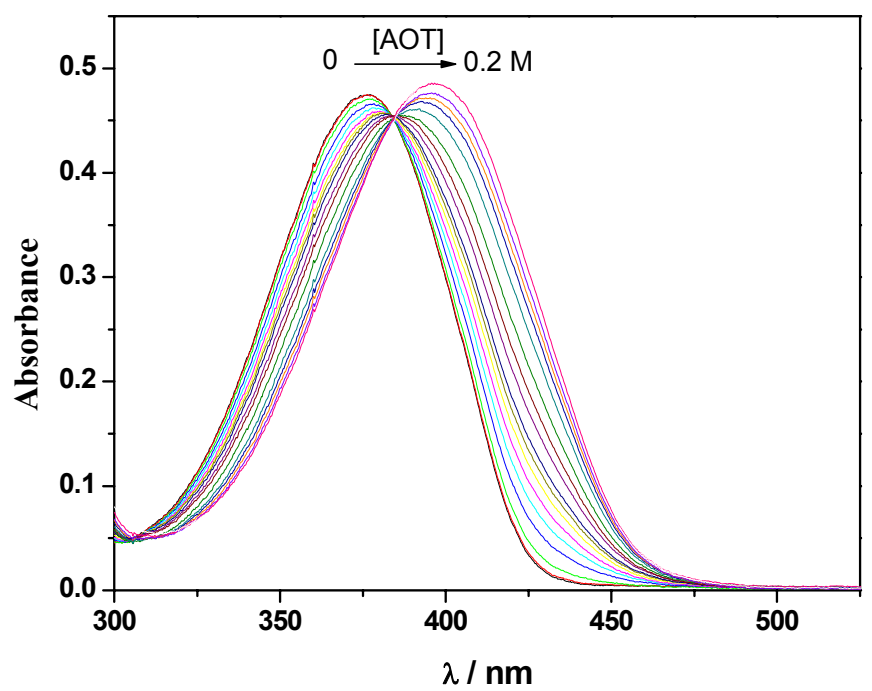

Figure 1. Absorption spectra of $o$-NA in $n$-heptane/AOT at different AOT concentrations at $\mathrm{W}_{S}$ $=0,[o-\mathrm{NA}]=8.9 \times 10^{-5} \mathrm{M}, \mathrm{T}=25^{\circ} \mathrm{C}$. 
The spectrum of the fully bound $o$-NA is red shifted by $24 \mathrm{~nm}$ regarding the initial spectrum of $o$-NA in $n$-heptane. Taking into account the studies in pure solvents ${ }^{17}$ such a red shift can be partly interpreted owing to the greater polarity of the micelle interface with regard to the organic solvent ${ }^{12}$ but also because the hydrogen bond acceptor ability of the polar heads of the surfactant. ${ }^{17-20}$ Thus, in this system, $o$-NA is acting as hydrogen bond donor through the $\mathrm{NH}_{2}$ group.

Figures 2 and 3 show typical spectra of $o$-NA in $n$-heptane/AOT nonaqueous reverse micelles as a function of AOT concentration at $\mathrm{W}_{S}=2$, for GY and DMA respectively. The other polar solvents investigated, namely EG, FA and DMF, present a similar behavior so the results are not shown. As it can be seen, in all the systems studied the features are the same as those shown in Figure 1. Thus, we are quite confident than in all the nonaqueous AOT reverse micelles, $o$-NA experiences the equilibrium process invoked above and in n-hexane/AOT/water reverse micelles. ${ }^{17}$

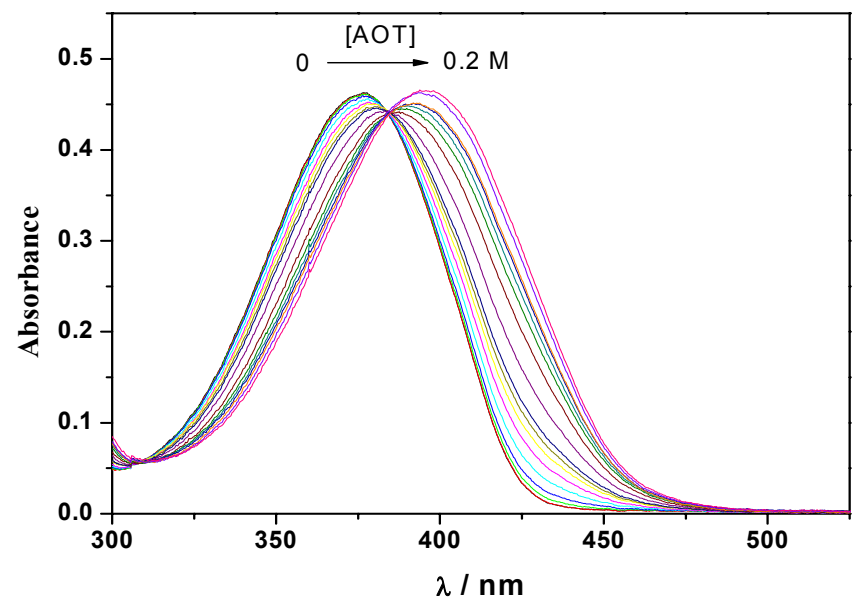

Figure 2. Absorption spectra of $o$-NA in $n$-heptane/AOT/GY at different AOT concentrations at $\mathrm{W}_{S}=2,[o-\mathrm{NA}]=8.6 \times 10^{-5} \mathrm{M}, \mathrm{T}=25^{\circ} \mathrm{C}$.

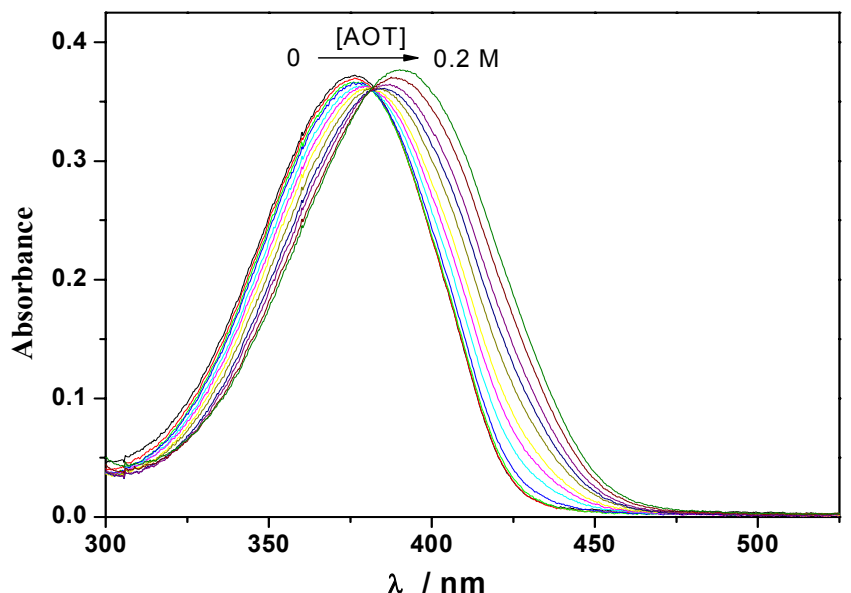

Figure 3. Absorption spectra of $o$-NA in $n$-heptane/AOT/DMA at different AOT concentrations at $\mathrm{W}_{S}=2,[o-\mathrm{NA}]=7.0 \times 10^{-5} \mathrm{M}, \mathrm{T}=25^{\circ} \mathrm{C}$. 
Since the $o$-NA seems to associate to AOT by hydrogen bond interaction, we have determined the strength of this association in every system investigated through the binding constant $\left(\mathrm{K}_{\mathrm{b}}\right)$.

To calculate $\mathrm{K}_{\mathrm{b}}$ between AOT reverse micelle and $n$-heptane, we will use the pseudophase model. ${ }^{6,34,36,50}$ This model considers the reverse micelle as a distinct pseudophase whose properties are independent of the AOT concentration and are only determined by the value of the characteristic parameter $\mathrm{W}_{S}$. In this model, only two solubilization sites are considered, that is, the external solvent and the reverse micelle interface (i.e. all the surfactant molecules). Thus, the distribution of $o$-NA between the micelles and the external solvent pseudophase can be expressed in terms of the binding constant $\mathrm{K}_{\mathrm{b}}$ showed in equation 1 :

$$
\mathrm{K}_{\mathrm{b}}=\frac{[\mathrm{o}-\mathrm{NA}]_{\mathrm{b}}}{[\mathrm{o}-\mathrm{NA}]_{\mathrm{f}}[\mathrm{AOT}]}
$$

Where $[o-\mathrm{NA}]_{\mathrm{b}}$ is the analytical concentration of the substrate incorporated to the reverse micelle, $[o-\mathrm{NA}]_{\mathrm{f}}$ is the concentration of the substrate in the organic solvent, and [AOT] is the micellized surfactant (total AOT concentration minus the "operational CMC" $\cong 10^{-4} \mathrm{M}$ obtained using the emission bands shift with the AOT concentration of acridine orange base at $\mathrm{W}_{S}=2$ ). ${ }^{33}$ This equation applies at a fixed value of $\mathrm{W}_{\mathrm{s}}$ and when $[o-\mathrm{NA}]_{\mathrm{T}}<<[\mathrm{AOT}]$ where $[o-\mathrm{NA}]_{\mathrm{T}}$ is the probe analytical concentration.

To calculate $\mathrm{K}_{\mathrm{b}}$ we have used equation $2:^{17}$

$$
\frac{[\mathrm{o}-\mathrm{NA}]_{\mathrm{b}}}{[\mathrm{o}-\mathrm{NA}]_{\mathrm{f}}}=\mathrm{K}_{\mathrm{b}}[\mathrm{AOT}]
$$

To calculate the terms $[o-\mathrm{NA}]_{\mathrm{b}}$ and $[o-\mathrm{NA}]_{\mathrm{f}}$ in every system studied, we measure the absorbance, A, at $\lambda_{\max }$ for the free and bound solute, at each [AOT]. Thus, the ratio $[o-\mathrm{NA}]_{\mathrm{b}} /[o-$ $\mathrm{NA}]_{\mathrm{f}}$ is calculated solving equations 3 and 4 for a given constant $o$-NA concentration and being $\mathrm{A}_{376}$ and $\mathrm{A}_{400}$ the measured absorbance values for each [AOT].

$$
\begin{aligned}
& \mathrm{A}_{376}=\varepsilon_{\mathrm{f}}{ }^{376} \times[o-\mathrm{NA}]_{\mathrm{f}}+\varepsilon_{\mathrm{b}}{ }^{376} \times[o-\mathrm{NA}]_{\mathrm{b}} \\
& \mathrm{A}_{400}=\varepsilon_{\mathrm{f}}{ }^{400} \times[o-\mathrm{NA}]_{\mathrm{f}}+\varepsilon_{\mathrm{b}}{ }^{400} \times[o-\mathrm{NA}]_{\mathrm{b}}
\end{aligned}
$$

The values of $\varepsilon_{\mathrm{f}}^{376}$ and $\varepsilon_{\mathrm{f}}^{400}$ are calculated from the spectrum of $o$-NA in $n$-heptane. The $\varepsilon_{\mathrm{b}}{ }^{376}$ and $\varepsilon_{\mathrm{b}}{ }^{400}$ are determined from the spectrum of $o$-NA at high AOT concentration (i.e. 0.1 M corresponding to $\approx 100 \%$ binding).

The plots of $[o-\mathrm{NA}]_{\mathrm{b}} /[o-\mathrm{NA}]_{\mathrm{f}} v s[\mathrm{AOT}]$ gave very good straight lines in every reverse micelle investigated. Figure 4 shows a typical plot for $n$-heptane/AOT/DMA reverse micelle at $\mathrm{W}_{S}=2$. From the slope of these plots, the value of $\mathrm{K}_{\mathrm{b}}$ can be calculated in the range of [AOT] concentrations where the equilibrium between the bound and free nitroaniline was 
observed. ${ }^{17,18,36}$ A linear regression analysis leads to the $K_{b}$ values reported in Table 1. This Table shows the value of $\mathrm{K}_{\mathrm{b}}$ obtained for these nonaqueous AOT reverse micelles at $\mathrm{W}_{S}=2$. Also, the value for $\mathrm{W}_{S}=0$ and $\mathrm{W}_{0}=2$ are included for comparison. It must be noted that the $\mathrm{K}_{\mathrm{b}}$ value reported in this work match perfectly the value obtained previously for $n$-hexane/AOT reverse micelles as expected. ${ }^{17}$

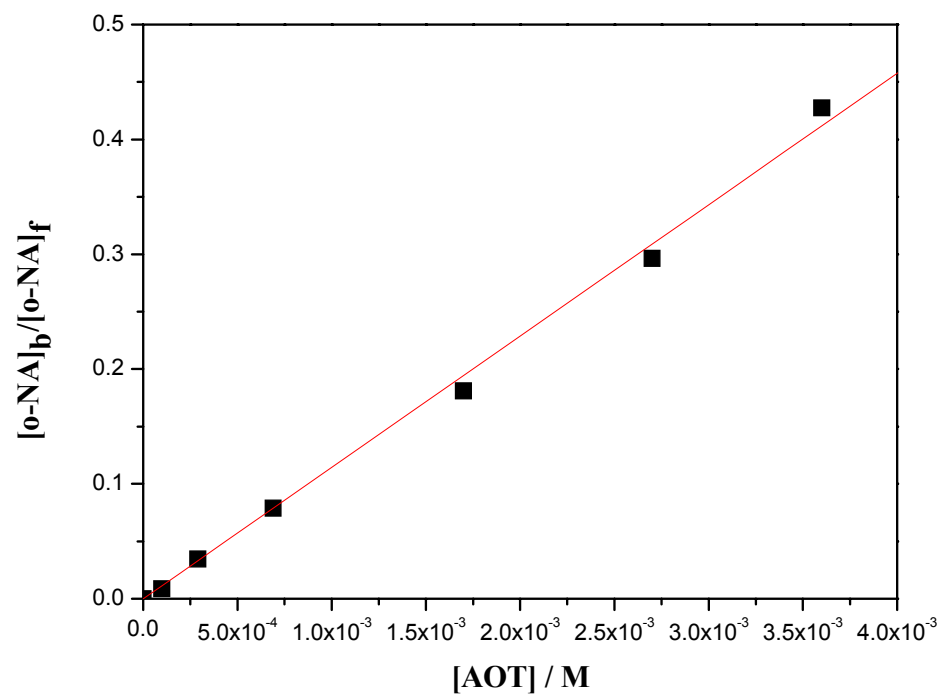

Figure 4. $[o-\mathrm{NA}]_{\mathrm{b}} /[o-\mathrm{NA}]_{\mathrm{f}}$ as a function of AOT concentration in $n$-heptane/AOT/DMA at $\mathrm{W}_{S}=$ $2,[o-\mathrm{NA}]=6 \times 10^{-5} \mathrm{M}, \mathrm{T}=25^{\circ} \mathrm{C}$.

Table 1. Binding constants of $o$-NA in different $n$-heptane/AOT reverse micelles systems at $\mathrm{W}_{S}=2$

\begin{tabular}{cccccccc}
\hline $\begin{array}{c}\text { Polar } \\
\text { solvent }(\alpha)^{\mathrm{a}}\end{array}$ & $\begin{array}{c}\text { GY } \\
(1.21)\end{array}$ & $\begin{array}{c}\text { Water } \\
(1.17)\end{array}$ & $\begin{array}{c}\text { EG } \\
(0.90)\end{array}$ & $\begin{array}{c}n \text {-heptane/AOT } \\
\mathrm{W}_{S}=0\end{array}$ & $\begin{array}{c}\text { FA } \\
(0.71)\end{array}$ & $\begin{array}{c}\text { DMF } \\
(0.0)\end{array}$ & $\begin{array}{c}\text { DMA } \\
(0.0)\end{array}$ \\
\hline $\mathrm{K}_{\mathrm{b}} / \mathrm{M}^{-1}$ & $40 \pm 2$ & $54 \pm 3$ & $62 \pm 4$ & $70 \pm 5$ & $77 \pm 5$ & $100 \pm 10$ & $114 \pm 10$ \\
\hline
\end{tabular}

${ }^{\mathrm{a}}$ From reference ${ }^{51}$.

The order of the $\mathrm{K}_{\mathrm{b}}$ values follows: $\mathrm{GY}<$ water $<\mathrm{EG} \sim \mathrm{W}_{S}=0 \sim \mathrm{FA}<\mathrm{DMF} \sim$ DMA (Table 1). At first glance it was expected that the order of the $K_{b}$ values should be in accordance to their hydrogen bond donor ability as measured by Kamlet and Taft's $\alpha$ scale (Table 1 ) ${ }^{51}$ Clearly, the results cannot be explained by considering only this solvent property because the $\mathrm{K}_{\mathrm{b}}$ value for $\mathrm{W}_{S}=0$ where no polar solvent is present, and was similar to the values for EG and FA.

In order to interpret our results, it was crucial to consider which part of the surfactant was involved in the polar solvent-AOT interaction in every nonaqueous AOT reverse micelles. Thus, the $o$-NA solubilization must be described in terms of: i) solvent - solute; ii) solvent- AOT headgroups and, iii) solute-AOT headgroup and the corresponding counterions interactions. Since it was already known that the polar solvent structure was dramatically disrupted upon encapsulation because the strong polar solvent - surfactant interaction, ${ }^{48}$ we did not consider the 
solvent - solute interaction in our interpretation. The interactions with the polar head of AOT and the counterions seem to be the main driving force to incorporate $o$-NA to the reverse micelles.

The hydrogen bond interaction between $o$-NA and the AOT headgroup is responsible for the $\mathrm{K}_{\mathrm{b}}$ value obtained at $\mathrm{W}_{S}=0$ as explained before. ${ }^{17}$ It was also demonstrated that the presence of water in the reverse micelles made the $\mathrm{K}_{\mathrm{b}}$ value diminish because of competition between $-\mathrm{NH}$ group and water as solvating agents for the AOT headgroup. ${ }^{17-19}$ We have shown that water and GY bind through hydrogen bonds to the $\mathrm{SO}_{3}{ }^{-}$group of AOT removing the $\mathrm{Na}^{+}$counterions from the interface. ${ }^{48}$ Also, the strength of this interaction is greater for GY than water. ${ }^{35,37}$ On the other hand, EG penetrates to the lipophilic side of the interface and interacts through hydrogen bond mainly with the AOT's $\mathrm{C}=\mathrm{O}$ group. Thus, EG interacts weakly with the $\mathrm{Na}^{+}$counterion which seems to be close to the AOT sulfonate group as in the case of $\mathrm{W}_{S}=0 .{ }^{48}$ In light of the above, we believe that $o$-NA has to interact by hydrogen bonding with the AOT sulfonate group rather than with the AOT's $\mathrm{C}=\mathrm{O}$ group because the $\mathrm{K}_{\mathrm{b}}$ values obtained are lower for $\mathrm{GY}$ and water than EG. It seems that the competition for the AOT sulfonate solvation between $-\mathrm{NH}$ and water or GY dominates the binding process. $o$-NA in EG/AOT reverse micelles, where EG which binds to the AOT carbonyl group, has a $\mathrm{K}_{\mathrm{b}}$ value similar to the system without polar solvent addition $\left(\mathrm{W}_{S}=0\right)$. This result confirms that the AOT sulfonate group was the part of the surfactant structure involved in the hydrogen bond interaction with $o$-NA.

FA is a "special" solvent since we demonstrated that FA encapsulated by AOT reverse micelles, interacts strongly with the $\mathrm{Na}^{+}$counterions and the sulfonate group of the surfactant through electrostatic interactions maintaining their hydrogen bond network present in the FA bulk. $^{42}$ Thus, it was expected, and actually observed, that the $\mathrm{K}_{\mathrm{b}}$ value in this system was similar to the one obtained at $\mathrm{W}_{S}=0$ because the sulfonate group was involved in an electrostatic interaction in both reverse micelles.

On the other hand, an interesting situation was observed when DMF and DMA were sequestrated by the reverse micelles since the $K_{b}$ values obtained were the highest. We previously demonstrated $^{48}$ that DMF and DMA encapsulated inside the reverse micelles, interact neither with the $\mathrm{C}=\mathrm{O}$ nor with the $\mathrm{SO}_{3}{ }^{-}$groups but their weakly bulk associated structure breaks because of coordination with $\mathrm{Na}^{+}$. As their resonance structure favored inside the reverse micelles is the nonionic one, it was suggested that DMF and DMA can complex the $\mathrm{Na}^{+}$ions through their amide groups. Thus, the sulfonate group can receive a hydrogen bond interaction from $o$-NA. Moreover, it was shown that the micropolarity of the AOT reverse micelle interface was greater than that corresponding to the bulk DMF and DMA. ${ }^{33}$ These facts explain satisfactorily the high values for the $\mathrm{K}_{\mathrm{b}}$ values obtained and confirm that the sulfonate group was "bare" in these reverse micelles and consequently more able to hydrogen bond to the solute. 


\section{Conclusions}

We have determined the binding of $o$-NA to the micellar interface of $n$-heptane/AOT/polar solvent reverse micelles using the water, EG, FA, GY, DMA and DMF. The study was performed following the solvatochromic behavior of $o$-NA in the AOT nonaqueous reverse micelles by using absorption UV-visible spectroscopy. The binding constant can be calculated through the changes in the UV spectra, since the bound molecules have different maxima and are shifted bathochromically from the value in $n$-heptane. The values of $\mathrm{K}_{\mathrm{b}}$ calculated follow the order $<$ water $<$ EG $\sim \mathrm{W}_{S}=0 \sim \mathrm{FA}<\mathrm{DMF} \sim \mathrm{DMA}$.

The results were explained by considering the different parts of the AOT polar headgroup that were involved in the polar solvent-AOT interaction. Moreover it was demonstrated that the $o$-NA - AOT hydrogen bond interaction was with the AOT sulfonate moiety. Thus, the more accessibility this group has for hydrogen bonding the larger the $o$-NA $\mathrm{K}_{\mathrm{b}}$ value.

\section{Experimental Section}

Materials. All chemicals and solvents were obtained from Aldrich or Sintorgan and are $99.9 \%$ purity or HPLC grade quality. AOT was dried under reduced pressure, over $\mathrm{P}_{2} \mathrm{O}_{5}$ until constant weight. The UV-vis spectra of 1-methyl-8-oxyquinolinium betaine (a solvatochromic probe) in the presence of AOT reverse aggregates showed that the surfactant was free of acidic impurities, which would have greatly reduced the intensity of the solvatochromic $B_{1}$ band at $502 \mathrm{~nm} .{ }^{12,52}$

Methods. The stock solutions of AOT in the hydrocarbon solvent were prepared by mass and volumetric dilution. To obtain optically clear solutions they were shaken in a sonicating bath and, the polar solvent was added using a calibrated microsyringe. The amount of polar solvent present in the system is expressed as the molar ratio between polar solvent and the AOT $\left(\mathrm{W}_{S}=\right.$ [Polar solvent]/[AOT]) and was kept constant and equal to 2 in every system investigated.

To introduce the probe, a $0.01 \mathrm{M}$ solution of $o$-NA was prepared in methanol (Sintorgan HPLC quality). The appropriate amount of this solution to obtain a given concentration $\left(10^{-5} \mathrm{M}\right)$ of the probe in the micellar medium was transferred into a volumetric flask, and the methanol was evaporated by bubbling dry $\mathrm{N}_{2}$; then, the AOT reverse micelles solution was added to the residue to obtain a $[\mathrm{AOT}]=0.5 \mathrm{M}$. The stock solution of AOT $0.5 \mathrm{M}$ and the probe molecules in $10^{-5} \mathrm{M}$ concentration were agitated in a sonicating bath until the microemulsion was optically clear. To the cell baring $2 \mathrm{~mL}$ of $o$-NA, of the same concentration in $n$-heptane, was added the appropriate amount of stock solution to obtain a given concentration of AOT in the micellar media. Therefore, the absorption of the molecular probe was not affected by dilution.

General. UV/visible spectra were recorded using a spectrophotometer Shimadzu 2401 with a thermostated sample holder. The path length used in absorption experiments was $1 \mathrm{~cm}$. 
To determine the value of $\mathrm{K}_{\mathrm{b}}$, all experimental points were measured three times with different prepared samples. The pooled standard deviation was less than 5\%. In all the cases, the temperature was kept at $25 \pm 0.2{ }^{\circ} \mathrm{C}$.

\section{Acknowledgments}

Financial support from the Consejo Nacional de Investigaciones Científicas y Técnicas (CONICET), Universidad Nacional de Río Cuarto, Agencia Nacional de Promoción Científica y Técnica and Agencia Córdoba Ciencia is gratefully acknowledged. JJS, NMC, RDF, MAB hold a research position at CONICET.

\section{References}

1. (a) Lehn, J-M. in "Frontiers in Supramolecular Organic Chemistry y Photochemistry", Schneider H-J, Dürr H. Eds., VCH, Weinheim, 1991. (b) Kuroiwa, K.; Oda, N.; Kimizuka, N. Sci. Tech. Adv. Mat. 2007, 7, 629.

2. Leodidis, E. B.; Hatton, T. A. J. Phys. Chem. 1990, 94, 6400.

3. Uskokovic, V.; Drofenik, M. Adv. Colloid Interface Sci. 2007, 133, 23.

4. Luisi, P. L.; Straub, B. E.; Reversed Micelles, Plenum, New York, 1984.

5. Yehta, A.; Aikawa, M.; Turro, N. J. Chem Phys. Lett. 1979, 63, 543.

6. Silber, J. J.; Biasutti, A.; Abuin, E.; Lissi, E. Adv. Colloid Interface Sci. 1999, 82, 189.

7. Tanaka, R.; Okasaki, K.; Tsuzuki, H., Chem. Lett. 1995, 1131.

8. Hasegawa, M.; Sugimura, T.; Shindo, Y.; Kitahara, A. Colloids Surfaces A: Physicochem. Eng. Aspects 1996, 109, 305.

9. Grand, D.; Dokutchaev, A. J. Phys. Chem. B 1997, 101, 3181.

10. De, T. P.; Maitra, A. Adv. Colloid Interface Sci. 1995, 59, 95.

11. Petit, C.; Lixon, P. ; Pileni, M. P. Langmuir 1991, 7, 2620.

12. Correa, N. M.; Biasutti, M. A.; Silber, J. J. J. Colloid Interface Sci. 1995, 172, 71.

13. Tamura, K.; Schelly, Z. A. J. Am. Chem. Soc. 1981, 103, 1018.

14. Leodidis, E. B.; Hatton, T. A. J. Phys. Chem. 1990, 94, 6411.

15. Wang, W.; Weber, M. E.; Vera, J. H. Biotech. \& Biong. 1995, 46, 343.

16. Rabie, H. R.; Vera, J. H. Ind. Eng. Chem. Res. 1996, 35, 365.

17. Correa, N. M.; Silber, J. J. J. Molec. Liquid 1997, 72, 163.

18. Correa, N. M.; Durantini, E. N.; Silber, J. J. J. Colloid Interface Sci. 1998, 208, 96.

19. Correa, N. M.; Durantini, E. N.; Silber, J. J. J. Colloid Interface Sci. 2001, 240, 573.

20. Zingaretti, L.; Correa, N. M.; Boscatto, L.; Chiacchiera, S. M.; Durantini, E. N.; Bertolotti, S. G.; Rivarola, C. R.; Silber, J. J. J. Colloid Interface Sci. 2005, 286, 245.

21. Martino, A.; Kaler, E. W. J. Phys. Chem. 1990, 94, 1627.

22. Ray, S.; Moulik, S. P. Langmuir 1994, 10, 2511. 
23. Fletcher, P. D. I.; Galal, M. F.; Robinson, B. H. J. Chem. Soc., Faraday Trans. I 1984, 80, 3307.

24. Fletcher, P. D. I.; Grice, D. D.; Haswell, S. J. Phys. Chem. Chem. Phys. 2001, 3, 1067.

25. Friberg, S. E.; Liang, P. Colloid Polym. Sci. 1986, 264, 449.

26. Rico, I.; Lattes, A. J. Colloid Interface Sci. 1984, 102, 285.

27. Arcoleo, V.; Aliotta, F.; Goffredi, M.; La Manna, G.; Turco Liveri, V. Mat. Sci. Eng. C 1997, 5, 47.

28. Riter, R. E.; Undiks, E. P.; Kimmel, J. R.; Levinger, N. E. J. Phys. Chem B 1998, 102, 7931 and references therein.

29. Riter, E. R.; Kimmel, J. R.; Undiks, E. P.; Levinger, N. E. J. Phys. Chem. B 1997, 101, 8292.

30. Mathew, C.; Saidi, Z.; Peyrelasse, J.; Boned, C. Phys. Rev. A 1991, 43, 873.

31. Lopez-Cornejo, P.; Costa, S. M. B. Langmuir 1998, 14, 2042.

32. Laia, C. A. T.; Lopez-Cornejo, P.; Costa, S. M. B.; d'Oliveira, J.; Martinho, J. M. G. Langmuir 1998, 14, 3531.

33. Falcone, R. D.; Correa, N. M.; Biasutti, M. A.; Silber, J. J. Langmuir 2000, 16, 3070.

34. Silber, J. J.; Falcone, R. D.; Correa, N. M.; Biasutti, M. A.; Abuin, E.; Lissi, E.; Campodonico, P. Langmuir 2003, 19, 2067.

35. Novaki, L. P.; Correa, N. M.; Silber, J. J.; El Seoud, O. A. Langmuir 2000, 16, 5573.

36. Falcone, R. D.; Correa, N. M.; Biasutti, M. A.; Silber, J. J. J. Colloid Interface. Sci. 2006, 296, 356.

37. El Seoud, O. A.; Correa, N. M.; Novaki, L. P. Langmuir 2001, 17, 1847.

38. Shirota, H.; Segawa, H. Langmuir 2004, 20, 329.

39. Raju, B. B.; Costa, S. M. B. Spectroc. Acta Part A 2000, 56, 1703.

40. Laia, C. A. T.; Brown, W.; Almgrem, M.; Costa, S. M. B. Langmuir 2000, 16, 8763.

41. Laia, C. A. T.; Costa, S. M. B. Langmuir 2002, 18, 1494.

42. Correa, N. N.; Pires, P. A. R., Silber, J. J.; El Seoud, O. J. Phys. Chem. B 2005, 109, 21209.

43. Atay, N. Z.; Robinson, B. H. Langmuir 1999, 15, 5026.

44. Hayes, D. G.; Gulari, E. Langmuir 1995, 11, 4695.

45. Novaira, M.; Moyano, F.; Biasutti, M. A.; Silber, J. J.; Correa, N. M. Langmuir 2008, 24, 4637.

46. Correa, N. M.; Levinger, N. E. J. Phys. Chem. B 2006, 110, 13050.

47. Falcone, R. D.; Silber, J. J.; Correa, N. M. Phys. Chem. Chem. Phys. 2009, 11, 11096.

48. Durantini, A. M.; Falcone, R. D.; Silber, J. J.; Correa, N. M. Chem. Phys. Chem. 2009, 10, 2034.

49. Kamlet, M. J.;Abboud, J. L. M.; Abraham, M. H.; Taft, R. W. J. J. Org. Chem. 1983, 48, 2877.

50. Encinas, M. V.; Lissi, E. Chem. Phys. Lett. 1986, 132, 545.

51. Marcus, Y. Chem. Soc. Rev. 1993, 409.

52. Correa, N. M.; Biasutti, M. A.; Silber, J. J. J. Colloid Interface Sci. 1996, 184, 570. 